\title{
Aerobic Bacteriological Profile in Cases of Ocular Infections in a Tertiary Care Hospital (Navodaya Medical College \& Research Centre, Raichur)
}

\author{
Namitha B.N ${ }^{1}$, Mahalakshmi ${ }^{2}$, Auchat Rao \\ Department Of Microbiology, Navodaya Medical College \& Reserch Centre, Raichur-584103.
}

\begin{abstract}
:
Background: Ocular infections are one of the common diseases of the eye.

The current trends in the etiology of ocular infections and their antibacterial susceptibility pattern must be updated to help the clinicians.

Objective: To identify the aerobic bacterial profile of ocular infections in patients attending Ophthalmology $O P D / I P D$.

Materials and Methods: 102 patients attending Ophthalmology OPD/IPD in Navodaya Medical College Hospital \& Research Centre were analysed from Nov 2010 to Sep 2011. Using predefined inclusion and exclusion criteria, samples were collected according to the standard protocol. These were cultured for microorganisms (aerobic bacterial) were identified. Drug susceptibility was done using Kirby Bauer disc diffusion method.
\end{abstract}

Results: The most common bacterial pathogen isolated were Staphylococcus aureus(32.8\%) followed by Staphylococcus epidermidis (25\%), other organisms isolated are Streptococcus pneumonia (14.1\%), Kiebsiella pneumonia (6.3\%), Escherichia coil (4.7\%).

Bacterial isolates were highly susceptible to Vancomycin(100\%), Gentamicin(94.3\%) among Gram positive organisms and among Gram negative organisms it is highly susceptible to Tobramycin(100\%) and Imipenem(90.9\%).

Conclusion: The study suggest that Staphylococcus aureus and Staphylococcus epidermidis are the most common etiological agents of Ocular infections. Most of the strains were sensitive to Vancomycin and Tobramycin.

Keywords: Ocular infections, Staphylococcus aureus, Staphylococcus epidermidis, Vancomycin, Tobramycin.

\section{Introduction}

Eye is the most important sensory organ concerned with the perception of vision. ${ }^{1}$ Ocular infections can affect different eye structures and their presentation and treatment vary accordingly. They present as: blepharitis, conjunctivitis, canaliculitis, dacrocystitis keratitis, scleritis, orbital cellulitis, endopthalmitis, panophthalmitis and other infections which are responsible for increased incidence of morbidity and blindness worldwide, their morbidity vary from self limiting trivial infection to sight threatening infection. ${ }^{2}$

Some of the ocular infections such as orbital cellulitis and panophthalmitis may lead to life threatening conditions. ${ }^{3}$ Actions can occur when tissues of the eye are exposed to pathogens not normally present; when the eye is damaged it allows the pathogens to overcome the natural defenses of the eye or in immunosuppressed patients where normal flora may become opportunistic can be caused by bacteria, fungi, parasites or viruses. ${ }^{4}$

\section{Objectives}

To study the aerobic bacteriological profile of ocular infections and their antibiotic sensitivity pattern in tertiary care hospital (Navodaya medical college hospital and research centre) Raichur.

Objectives:

1. To study the aerobic bacteriological profile in cases of ocular infections.

2. To study the susceptibility pattern to commonly used antibiotics

\section{Materials And Methods}

Place of study: The present study was undertaken at Navodaya Medical College Hospital and Research centre, Raichur.

Sample size: 102 cases.

Study Period: The period of study was from November 2010 to September 2011.

Methodology: The subjects in this study include those who have fulfilled the following inclusion and exclusion 
criteria.

\section{Inclusion criteria:}

1. Clinically diagnosed cases of ocular infections attending Outpatient Department and Inpatient Department of Ophthalmology, Tertiary Care Centre (Navodaya Medical College Hospital and Research Centre), Raichur.

2. Patients not on antibiotics (either topical or systemic) will be included in the study.

3. Patients not responding to antibiotics.

\section{Exclusion criteria:}

1. Non infectious etiology of ocular diseases.

Study cases: After clinical diagnosis of ocular infection made by Ophthalmologist, specimens were collected with the help of Ophthalmologist. Samples like eyelid swab, pus from Dacrocystitis, corneal scrapings, comeal swab, and tissue specimens from 102 clinically diagnosed cases of ocular infections from patients attending department of Ophthalmology, Tertiary Care Centre (Navodaya Medical College Hospital and Research Centre), Raichur. Informed verbal consent was obtained from all patients enrolled. Clinical/demographic data were collected using a prepared questionnaire.

\section{Sample collection ${ }^{12}$ :}

Eye lid swab was collected using sterile cotton tipped swab moistened with sterile peptone water which was rolled over the eye lid margin from media to lateral side and back again.

Conjunctival swab was collected using dry sterile cotton tipped swab by asking the patient to look up, the lower lid was pulled down using thumb with an absorbing tissue paper and the swab was rubbed over the lower conjunctival sac from medial to lateral side and back again.

Pus from lacrimal sac was collected using dry sterile cotton tipped swab either by applying pressure over the lacrimal sac and allowing the purulent material to reflux through the lacrimal punctum or by irrigating the lacrimal drainage system with sterile saline called as Lacrimal Syringing and collecting the sample from the refluxing material ensuring that the lid margins or the conjunctiva were not touched. In cases of acute lacrimal abscess on chronic Dacryocystitis pus was drained and taken on a dry sterile cotton tipped swab.

Corneal scrapings was collected after instilling 2 to 3 drops of local anesthetic into the conjunctiva, patient is asked to wait for 2 to 3 min and corneal surface was cleaned for debris and discharge using dry sterile cotton tipped swab and with the help of slit lamb the edge of the ulcer was scraped using sterile disposable scalpel blade no 15 taking care not to perforate the cornea.

The number of swabs and scrapings collected depended on the material obtained on swab stick or the blade, at least a minimum of 2 swabs or scrapings and maximum of 4 swabs or scrapings were collected, labelled and were inoculated immediately bed side into various culture media as mentioned below.

The corneal button, the lacrimal sac, chalazion removed by surgery was sent to the microbiology laboratory in a sterile container filled with sterile normal saline immediately.

The corneal button and the lacrimal sac tissue were labelled and processed after cutting into small bits using sterile scalpel blade and sterile foreceps in a small sterile petridish following all aseptic precautions and processed immediately Aerobic growth cultured ${ }^{13}$ and identified. Antimicrobial susceptibility tests ${ }^{14,15}$ done.

\section{Results}

In the present study 102 clinically diagnosed cases of Ocular infections of all ages and both sex attending Ophthalmology OPD and IPD of Navodaya Medical college, Raichur during the study period were taken.

TABLE 1: Total culture report.

\begin{tabular}{|l|l|l|l|l|}
\hline Total samples & Positive & Percentage & Negative & Percentage \\
\hline 102 & 75 & 73.6 & 27 & 26.4 \\
\hline
\end{tabular}

The above table shows that out of 102 samples studied culture yielded positive in majority of samples i.e. $75(73.6 \%)$ samples and the rest $27(26.4 \%)$ in negative for culture.

TABLE 2: Total number of isolates obtained from ocular infections

\begin{tabular}{|l|l|l|}
\hline Total samples & Total organisms isolated & Percentage \\
\hline 102 & 87 & 85.3 \\
\hline
\end{tabular}


Out of 102 cases of eye infection studied which included patients suffering from Chalzizion, Conjunctivitis, Keratitis, Dacrocystitis, Endophalmitis and cubical cellulitis, 75 samples had growth and the isolation rate is $73.6 \%$ and the ...organisms isolated from these 75 samples is $87(85.2 \%)$.

TABLE 3: Correlation of Gram stain with culture results

\begin{tabular}{|l|l|l|l|}
\hline \multirow{2}{*}{ Gram stain } & \multicolumn{2}{|l|}{ Culture } & \multirow{2}{*}{ Total } \\
\cline { 2 - 3 } & Positive & Negative & \\
\hline Positive & 27 & 10 & 37 \\
\hline Negative & 31 & 34 & 65 \\
\hline Total & 58 & 44 & 102 \\
\hline
\end{tabular}

$$
X^{2}=5.156, \mathrm{df}=1, \mathrm{p}<0.022
$$

Sensitivity and specificity

$\begin{array}{ll}\text { Variable } & \text { Value } \\ \text { Sensitivity } & \\ \text { Specificity } & 46.55 \% \\ \text { Positive Predictive Value } & 72.97 \%\end{array}$

Positive Predictive Value $72.97 \%$

Negative Predictive Value $52.31 \%$

Out of 37 Gram stain positive result, 27 correlated with culture ......Gram stain negative results, 31 positive with culture results with ......and sensitivity of $46.55 \%$ with significant $\mathrm{p}$ value 0022 .

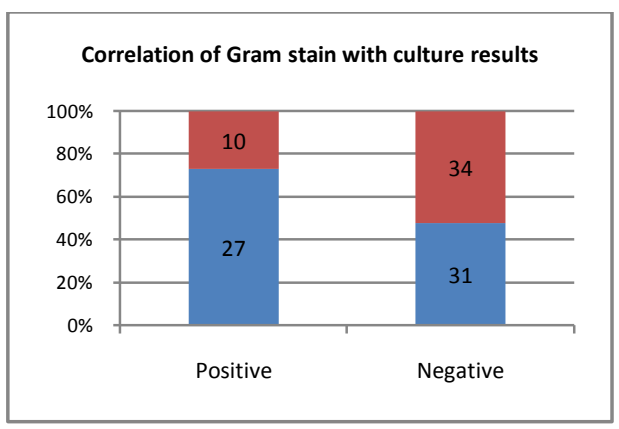

GRAPH 1: showing the correlation of Gram stain with culture.

TABLE 4: Positivity Rate of Ocular Infection According to Clinical Condition

\begin{tabular}{|l|l|l|l|}
\hline Clinical condition & $\begin{array}{l}\text { Total number of } \\
\text { samples }\end{array}$ & $\begin{array}{l}\text { Number of samples with } \\
\text { growth }\end{array}$ & Percentage \\
\hline Eyelid infections & 9 & 6 & \\
\hline Conjunctivities & 6 & 3 & \\
\hline Keratitis & 55 & 41 & \\
\hline Dacrocystitis & 30 & 23 & \\
\hline Orbital cellulitis & 2 & 2 & \\
\hline Total & 102 & 75 & \\
\hline
\end{tabular}

The maximum yield is obtained from orbital cellulitis cases ....studied, 2(100\%) yielded growth followed by dacrocystitis cases ...... studied $23(76.7 \%$ ) yielded growth, in keratitis samples,....

$41(74.5 \%)$ showed growth, in eyelid infections out of 9 samples studied,......yielded growth, in conjunctivitis cases out of 6 samples studied .......organisms. 


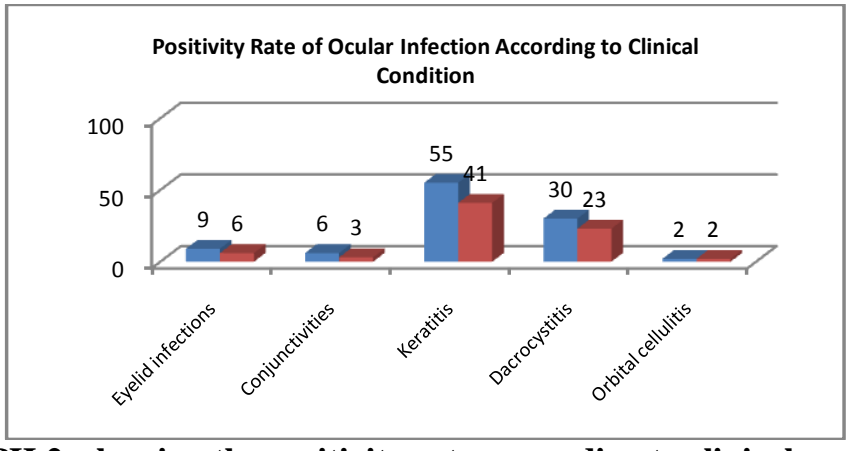

GRAPH 2: showing the positivity rates according to clinical condition

TABLE 5 : Distribution of bacterial isolates according to their spectrum

\begin{tabular}{|l|l|l|}
\hline Bacterial isolates & Number of isolates & Percentage \\
\hline Gram positive cocci & & \\
\hline Staphylococcus aureus & 21 & 32.8 \\
\hline Staphylococcus epidermidis & 16 & 25.0 \\
\hline Other CONS spp & 4 & 6.3 \\
\hline Streptococcus pneumoniae & 9 & 14.1 \\
\hline Non hemolytic Streptococcus & 1 & 1.6 \\
\hline Gram negative cocci & & \\
\hline Nil & & \\
\hline Gram positive bacilli & & \\
\hline Diphtheroids & 2 & 3.1 \\
\hline Gram negative bacilli & & \\
\hline Escherichia coli & 3 & 4.7 \\
\hline Atypical Escherichia coli & 2 & 3.1 \\
\hline Klebsiella pneumoniae & 4 & 6.2 \\
\hline Pseudomonas aeruginosa & 2 & 3.0 \\
\hline TOTAL & 64 & \\
\hline
\end{tabular}

Of the 87 isolates, 64(74\%) is bacterial isolates, the most frequent is the Staphylococcus aureus 21(32.8\%) followed by Staphylococcus epidermidis 16(25\%), Streptococcus pneumoniae 9(14.1\%), other CONS spp and Streptococcus pneumoniae each 4 (6.3\%), Escherichia coli 3(4.7\%), Diphtheroids... Escherichia coli and Pseudomonas aeruginosa each 2(3.1\%) in descending order.

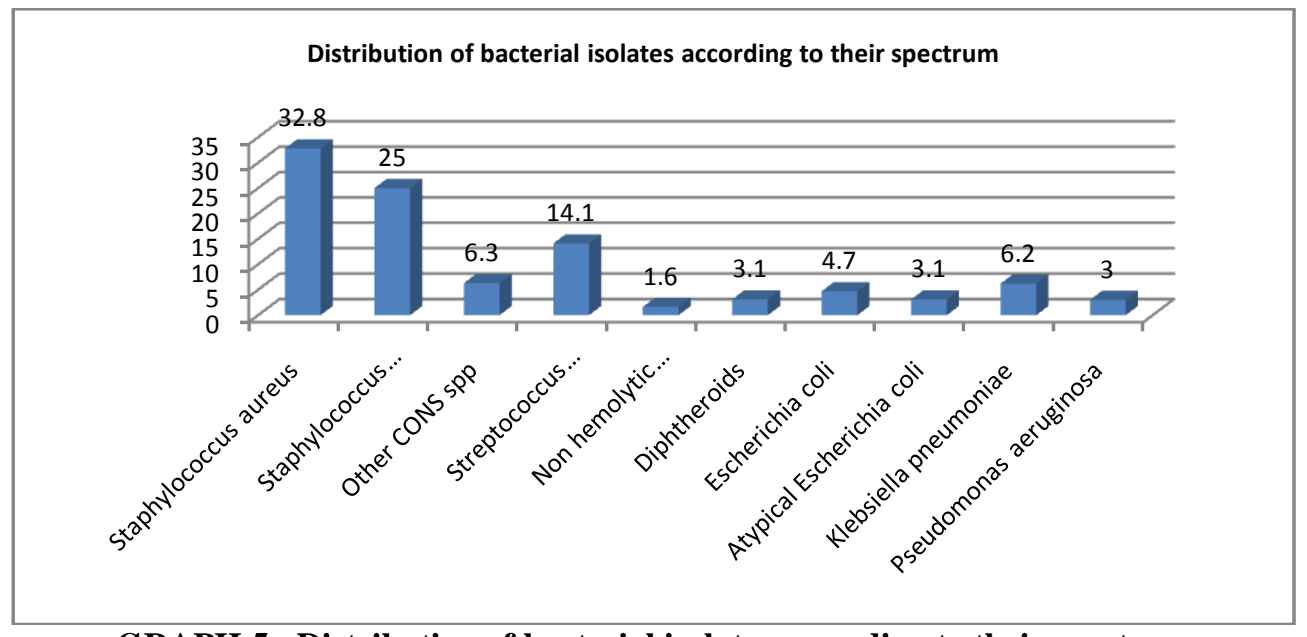

GRAPH 5 : Distribution of bacterial isolates according to their spectrum 
TABLE 6: Sample wise distribution of organisms

\begin{tabular}{|c|c|c|c|c|c|c|c|c|c|c|}
\hline Organisms & 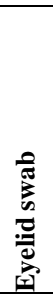 & 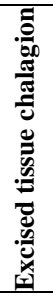 & 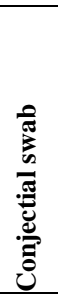 & 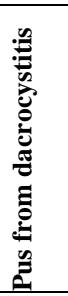 & 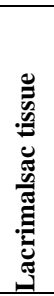 & 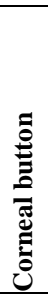 & 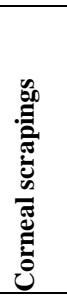 & $\frac{\vec{\sigma}}{\tilde{\sigma}}$ & 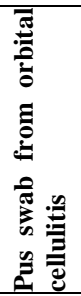 & 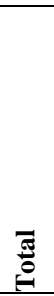 \\
\hline $\begin{array}{l}\text { Staphylococcus } \\
\text { aureus }\end{array}$ & 1 & 1 & 1 & 6 & & 1 & 4 & 5 & 2 & 21 \\
\hline $\begin{array}{l}\text { Staphylococcus } \\
\text { epidermidis }\end{array}$ & 3 & & 1 & 1 & & & 3 & 8 & & 16 \\
\hline $\begin{array}{l}\text { Other CONS } \\
\text { spp }\end{array}$ & & & & 1 & 1 & & 2 & & & 4 \\
\hline $\begin{array}{l}\text { Staphylococcus } \\
\text { pneumonia }\end{array}$ & & & & 3 & & & 5 & 1 & & 9 \\
\hline $\begin{array}{l}\text { Nonhemolytic } \\
\text { Staphylococcus }\end{array}$ & & & & & & & & 1 & & 1 \\
\hline Disphtheroids & & & & 2 & & & & & & 2 \\
\hline $\begin{array}{l}\text { Escherichia } \\
\text { coli }\end{array}$ & & & & 2 & 1 & & & 1 & & 3 \\
\hline $\begin{array}{l}\text { Atypical } \\
\text { Escherichia } \\
\text { coli }\end{array}$ & & & & 1 & & & & & & 2 \\
\hline $\begin{array}{l}\text { Klebsiella } \\
\text { Staphylococcus }\end{array}$ & & & & 3 & 1 & & & & & 4 \\
\hline $\begin{array}{l}\text { Pseudomonas } \\
\text { aeruginosa }\end{array}$ & & & & 2 & & & & & & 2 \\
\hline Total & 4 & 1 & 3 & 23 & 3 & 2 & 27 & 22 & 2 & 87 \\
\hline Percentage & 4.6 & 1.1 & 3.4 & 26.4 & 3.4 & 2.3 & 31.0 & 25.3 & 2.3 & 100 \\
\hline
\end{tabular}

The percentage of isolation from different samples is as follows:

From eyelid swab out of 4(4.6\%) isolates, Staphylococcus epidermidis (3) is the most common isolate followed by Staphylococcus aureus (1).From chalazion tissue 1(1.1\%) isolate is Staphylococcus aureus.

From conjunctival swab out of 3(3.4\%) isolates, 1 Staphylococcus aureus, 1 Staphylococcus epidermidis \& 1 Mucor spp are isolated.

Pus from Dacrocystitis, out of 23(26.4\%) isolates, 6 Staphylococcus aureus, Streptococcus pncumoniae and Klebsiella pneumoniae 3 each, Diphtheroids, Pseudomonas aeruginosa and Escherichia coli 2 each, Staphylococcus epidermidis, Other CONS spp, Atypical Escherichia coli, Rhizopus spp and Alternaria spp 1 each are isolated.

From lacrimal tissue out of 3(3.4\%) isolates, Other CONS spp, Escherichia coli and Klebsiella pneumoniae 1 each are isolated.

From corneal button out of 2(2.3\%) isolates, Staphylococcus aureus and Alternaria spp l each are isolated. ,

From corneal scrapings out of $27(31 \%)$ isolates, 5 Streptococcus pneumoniae, Staphylococcus aureus, Staphylococcus epidermidis and Rhizopus spp 3 each, Other CONS spp.

From corneal swab out of 22(25.3\%) isolates 8 Staphylococcus epidermidis, 5 Staphylococcus aureuse, Streptococcus pneumoniac, Nonhemolytic

\section{Discussion}

In the present study, 102 clinically diagnosed cases of ocular infections attending Ophthalmology out-patient and in patient department at Navodaya Medical College Hospital and Research centre, Raichur from Nov 2010 to Sep 2011 was studied. The pattern of relative incidence of various factors varies in different studies Distribution of cases according to sen the present study males $(57.5 \%)$ were affected more than females (42.2\%) Correlates with the study conducted by Sharma VK et al Darek V Kunimoto et al"

The predominance of ocular infections in males can be attributed to their greater involvement in outdoor activities, thus more prone to corneal injury with external agenis.

In the present study the mean age for ocular infections is 45.20 years-with standard deviation (SD) of 18.60 (range 4months to 78 years) which almost correlated with the study by Gopinathan 19(U et 0.96 where majority of patients $64.4 \%$ belonged to younger age group in 16 to 49 years age group, the average age at presentation was $40.4+1-15.3$ Years,

Distribution of Clinical Diseases 
In the present study the commonest infection is keratitis 55(53.9\%), followed by Dacrocystitis $30(29.4 \%)$, eyelid infections $9(8.8 \%)$, conjunctivitis $6(5.9 \%)$ and orbital cellulitis $2(2.0 \%)$. Of the 55 cases of keratitis, 2 cases progressed to endophthalmftis and patients were taken for enucleation when corneal button was the sample provided. Dacrocystitis is the most common infection of lacrimal apparatus; the basis for this infection is blockage of lacrimal duct system resulting in accumulation tears and creation of a fertile environment for secondary bacterial 3 infection and dacryolith formation\$ In other studies by Modarres Sh et aLW ${ }^{8}$ Conjunctivitis was the most common presentation $(77.9 \%)$ and the least common was endophthalmjt,s (2.5\%) another study by Sherwal B I. et al ${ }^{11}$, the most common ocular infection was conjunctivitis $(59.2 \%)$ followed by keratitis $(53.34 \%)$

Distribution of bacterial isolates according to their spectrum

Tabl 4 OMP Comparative studies of Distribution of spectrum of bacterial isolates:

\begin{tabular}{|c|c|c|c|c|c|}
\hline Organism & $\begin{array}{l}\text { Khosravi AD } \\
\text { al 2007 Iran }\end{array}$ & $\begin{array}{l}\text { et Dumre } \quad \text { SP } \\
\text { al } 2008 \text { Nepal }\end{array}$ & $\begin{array}{l}\text { Ct Sherwal BL } \\
\text { al } 2008 \text { India }\end{array}$ & \begin{tabular}{l|l} 
et & $\begin{array}{l}\text { Ramesh } \\
\text { S et } 2010 \\
\text { Tamil }\end{array}$ \\
\end{tabular} & $\begin{array}{l}\text { Present } \\
\text { study } \\
\text { ard }\end{array}$ \\
\hline Staphylococcus aureus & $12.9 \%$ & $20 \%$ & $19.13 \%$ & $25.13 \%$ & $32.8 \%$ \\
\hline Staphylococcus epidermidis & - & 0 & $19.13 \%$ & - & $25 \%$ \\
\hline Streptococcus peurnoniae & $8.6 \%$ & $40 \%$ & $10.93 \%$ & $21.78 \%$ & $14.1 \%$ \\
\hline Other CONS spp & $32.9 \%$ & 0 & $1.65 \%$ & $18.29 \%$ & $6.3 \%$ \\
\hline Nonhaernolytic Streptococcus & 0 & 0 & 0 & 0 & $1.3 \%$ \\
\hline Diphilisroids & 0 & 0 & 0 & $1.25 \%$ & $3.1 \%$ \\
\hline Klebsiella spp & - & $1.5 \%$ & $2.74 \%$ & $3.9 \%$ & $6.3 \%$ \\
\hline Escherichia coil & $8.6 \%$ & 0 & $1.10 \%$ & $12.1 \%$ & $7.8 \%$ \\
\hline Pseudomonas aeruginosa & $24.2 \%$ & $4 \%$ & $4.92 \%$ & $3.45 \%$ & $3.1 \%$ \\
\hline
\end{tabular}

In the present study the most frequently isolated organism is Staphylococcus aureus (32.8\%) followed by Staphylococcus epidermidis (25\%), Streptococcus pneumoniae (14.1\%) other CONS spp (6.3\%) and nonhaemolytic Streptococcus (1.6\%), Among Gram negative bacilli Kiebsiella pneumoniae (6.3\%), Escherichia coil (4. , Atypical Escherichia coli (3.1\%) and Pseudomonas aeruginosa (3.1\%) and Diphtheroids (3.1\%).

In studies by Ramesh $\mathrm{S}$ et $\mathrm{al}^{3} \&$ Sherwal BL et $\mathrm{al}^{11}$ - $2 \mathrm{AStaphyiococcus}$ aureus were the most common isolate in ocular infections with $25 \%$ \& $19.31 \%$ incidence respectively in par with the present study where also Staphylococcus aureus is the most common isolate $(32.8 \%)$.

The other organism isolated in studies by the above two authors are Streptococcus pneumoniae

$21.78 \%$ \& $10.93 \%$ respectively (present study it is $14.1 \%$ ), other CONS spp, $21.78 \%$ \& $10.93 \%$ respectively (present study 6.3\%), Kiebsielia spp, 3.9\% \&2.74\% respectively (present study 6.3\%), Escherichja coil, $12.1 \%$ \& $1.10 \%$ respectively (present study $7.8 \%$ ), Pseudomonas aeruginosa, $3.45 \% \& 4.92 \%$ respectively (present study 3.1\%). Sherwal BL et al $^{11}$ isolated $19.3 \%$ Staphylococcus epidermidis (present study $25 \%$ ), Ramesh S et al isolated $1.25 \%$ Diptheroids, (present study $3.1 \%$ ) Study by Khosravi et al ${ }^{5}$. CONS was the most frequently isolated organism with frequency of $32.9 \%$ (present study $6.3 \%$ ).

Studies by Dumre SP et $\mathrm{al}^{7}$, Streptococcus pneumoniae was the most common isolate with the incidence of $34 \%$ (present study $14.1 \%)$.(03.03\%),

In the present study GPC are highly sensitive $(100 \%)$ to Vancomycin and Bacitracin. Gentamicin is $100 \%$ sensitive to Streptococcus pneumoniae \& nonhemolytic Streptococcus; it is $95.2 \%, 93.15 \%$ \& $75 \%$ sensitive to Staphylococcus aureus, Staphylococcus epidermidis \& other CONS spp respectively.

Erythromycin \& Clindamicin is $100 \%$ sensitive to Streptococcus pneumoniae \& nonhernolytic Streptococcus. They are intermitental ly sensitive to Staphylococcus aureus $(66.6 \% \& 87.7 \%)$, Staphylococcus epidermidis $(62.5 \%)$ and CONS $(50 \%$ \& $75 \%$ to Erythromycin \& Clindamicin respectively) Oxacillin \& Cephoxitin is $71.4 \%, 56.2 \%$ \& $50 \%$ sensitive to Staphylococcus aureus, Staphylococcus epidermidis \& other CONS spp respective iprofloxacin is $66.6 \%, 68.75 \%, 75 \%, 88.8 \%$ \& $100 \%$ sensitive to Staphylococcus aureus, Staphylococcus epidermidis, other CONS spp, Streptococcus nonhemolytic

Among GNB it is highly sensitive to Tobramycin (100\%), pet Cefepime, Piperacillin/Tazobactum and Imipenem each $88.8 \%$. Pseudomonas aeruginosa is highly sensitive to most of the drugs like Co-Ciprofloxacin, Gentamicin, Amikacin, Ceftazidime, Cefei Piperacillin Tazobactum, Imipenem.

In the present study Staphylococcus aureus (n21) is highly Vancomycin, Rifampicin and Bacitracin, 95.2\% sensitive to Tetracycline, $90.4 \%$ to Polymyxin B, $85.7 \%$ to Clindamycin, $76.1 \%$ Chloramphenicol, $714 \%$ to Oxacillin, $666 \%$ to Erythromycm $61.9 \%$ to Cotrimoxazole \& least sensitive to Penicillin $4.76 \%$..

Modarres Sh et al $^{\mathbf{8}}$ Staphylococcus aureus $(\mathrm{n}=97)$ is $87 \%, 83 \%, 7 \mathrm{f} \%$, and $0 \%$ sensitive to Vancomycin, Chioramphenicol, Gentamic, Cotrimoxazole \& Penicillin respectively.

In the present study Staphylococcus epidermidis is 100\% sensitive to Bacitracin, $9375 \%$ to Gentamicin 
\& Rifampicin, $875 \%$ to Tetracycline, $75 \%$ to Chloramphenicol, $68.75 \%$ to Ciproflos Erythromycin \& Clindamycin, $562 \%$ to Oxacillin \& Ceph Cotrimoxazole, least sensitive to Penicillin 12.5\%, in the study..kky 4/3.7., Staphylococcus epiderinidis is $87 \%, 81 \%, 54 \%, 41 \%$, 33\% \& Chloramphenjcol Vancomycin, Gentamicin, Erythromycin Cotrimoxa.zole \& Penicillin respectively.

In the present study Streptococcus pneumoige (n9) is $100 \%$ sensitive to Vancomycin Penicillin Gentamicin Oxacijjn, Erythromycin \& Clindamycin, 88.8\% to Ciprofloxa4n, Chioramphenicol \& Tetracycline $33.3 \%$ sensitive to Cotrimoxole Study by Modarres $\mathrm{Sb}^{\text {et }} \mathrm{al}^{8}$, Streptococcus pneumonigis $98 \%$ sensitive to Penicillin \& Erythromycjn, 96\%, 94\%, 44\% \& 33\% sensitive to Chioramphenicol, Ampici Ilin, Vancomycjn \& Cotrimoxazole respectively.

In the present study Gram negative enteric bacilli $(\mathrm{n}=9)$ is $100 \%$ sensitive to Tobramycin, $88.8 \%$ to Cefipime, \& Imipenem. 77.7\% to Gentarnicin \& Amikacin, 55.5\% to Cotrimoxazole Ciprofloxacjn Chioramphenicol \& Piperacillin $444 \%$ to Amoxyclav, Ceftriaxone, Cefuroxjme \& Cefta.zidime, in the study by Modarres Sh Ct M-7, Gram negative enteric bacilli is $94 \%$ i88\% \& $83 \%$ to Cotrimoxazole, Chloramphenicol \& Polymyxin B respectively, $73 \%$ sensitive to Gentamicin \& CarbjniciUin 66\% \& 16\% sensitiye to Amkacin \& Ampicillin respectively.

In the present study, Pseudomonas aeruginosa $(\mathrm{n}=2)$ is $100 \%$ sensitive to Cotrimoxazole, Ciprofloxacin, Gentamicin, Amikacin, Ceftazidime, Cefipime, Cefiriaxone Piperacillin, PiperacillinjTazobactam Tobramycin \& Imipenem. It is 50\% sensitive to Amoxyclav \& Cefuroxime, in the study by Modarres Sh et al", Pseudomonas aerugillosa is $99 \%$ sensitive to Polymyxin B, $88 \%$ sensitive to Gentamicin Anrijkacjn Tobramicjn33\% \& $11 \%$ sensitive to Cotrimoxazole \& Chioramphenicol respectively.

In the study by Khosrayj $\mathrm{AD}$ et $\mathrm{al}^{5} 61.7 \%, 55 \%$, \& $53 \%$ of GPC are sensitive to Tetracycline, Cephalothin \& Cefiriaxone respectively (in the present study Tetracycline has $86.97 \%$ coverage). All the tested GPC was resistant to Penicillin I. which is similar to the present study. The coverage of Vancomycin was 100\% to CONS, but 0\% to Staphylococcus aureus (in the present study all GPC has 100\% coverage to Vancomycin). $74.5 \%$ of GPC \& $82.6 \%$ of GNB was sensitive to Gentamicin (in the present study $94.3 \%$ of GPC \& $81.8 \%$ of GNB is sensitive to 2 Gentamicin.

\section{Conclusion}

Ocular infections are then major cause of ocular morbidity and modality which is a major public health problem in terms of visual compromise especially in developing countries like India.

Changes in bacterial resistance patterns have been a major problem in the effective management of ocular infections, better access to effective and safe topical antibiotics has been cited as the primary factor in improving patients outcomes and quality of life.

This study aims at isolating a variety of aerobic bacterial pathogens causing ocular infections and testing for the antibiotic susceptibility pattern of the aerobic bacterial pathogens isolated.

In conclusion, varity of organisms are implicated as causative agents of ocular infections. Of the various aerobic bacterial and fungal pathogens isolated Staphylococcus aureus was the most common bacterial pathogen isolated.

Antibiotic susceptibility pattern showed that most of the isolates were the sensitive agents and among Gram positive organisms Vancomycin was 100\% sensitive and the next sensitive drugs were Bacitracin, Gentamicin, Rifampicin and Penicillin being the least sensitive drug. Among Gram negative organism Tobramycin was the most sensitive drug (100\%) followed by Imipenem, Cefipime, Piperacillin/Tazobactum and least sensitive was to Chloramphenicol, Ceftriaxone and Amoxyclay.

This susceptibility pattern shows the need for broad spectrum antibiotics with greater antibacterial efficacy which are more sensitive than older.

\section{Bibliography}

[1]. Thielen TL, Castle SS, Terry JE. Anterior Ocular Infection: an overview of pathophysilolgy and treatment. Ann Pharmacother 2000; 34(2): 235-246.

[2]. Chirambo MC, Tielsch JM, West KP, Katz J. Blindness and visual impairment in Southern Malawi. BULL WHO 1986;64:567-72.

[3]. Ramesh S, Ramakrishnan R, Bharathi MJ, Amuthan M, Vishwanathan S. Prevalence of bacterial pathogens causing ocular infections in south India J Pathol Microbiol 2010; 53:281-6.

[4]. Sharma S. Ocular infections: Research in India. Indian J Med Microbilo 201; 28:91-4

[5]. Khosravi AD, Mehdinejad M, Heidari M. bacteriological findings in patients with ocular infection and antibiotic susceptibility patterns of isolated pathogens. Singapore Med J 2007; 48(8):741-3.

[6]. Duke-Elder S, Cook C. Embryology. In: Duke-Elder S. Eds. System of Ophthalmology, Vol III, Part 1. St. Louis, CV Mosby; 1963: 239-246.

[7]. Doane MG. Turnover and drainage of tars. Am J Ophthalmol 1984; 16(2): 111-114.

[8]. Modarres Sh, Lasheii A, Oskoii NN. Bacterial etiologic agents of ocular infection in children in the Islamic Republic of Iran. East Med H J 1998; 4(1):44-49. 
[9]. Gopinatha U, Garg P, Fernandes M, Sharma S, Athmanathan S, Rao GN. The epidemiological features and laboratory results of fungal keratitis. Cornea 2002; 21(6): 555-559.

[10]. Sharma VK, Purohit M, Vaidya S. Epidemiological study of mycotic keratitis. The internet Journal of Visual Science 2009; 6 (2).

[11]. Sherwal Bl, Verma AK. Epidemiology of ocular infection due to bacteria and fungus. A prospective study. JK Science 2008; 10 (3): $127-131$.

[12]. Gilmore MN, Chistopher N, chistopher N, Bowman RW, mCcULLEY Jp. Ocular Bacteriology Chapter 11 In: Albert DM, Miller JW, Azar DT, Blodi BA, Cohan JE, Perkins T. Albert \& Jakobiec's; Principles and Practice Ophthalmolgy $3^{\text {rd }}$ edition Volume 1. Saunders Elsevier; 2008:101-116.

[13]. Colle Jg, Marr W. Culture of Bacteria Chapter 6 In: Collee JG, Fraser AG, Marmion BP, Simmons A. Mackie and McCartney practical medical microbiology. Colle JG, Miles RS, Watt B. Tests for Identification of Bacteria. In: Collee JG, Fraser AG, Marmion BP, Simmons A. Mackie and McCartney practical medical microbiology. $14^{\text {th }}$ edition Edinburg Churchill Livingstone; 2007;131-149.

[14]. Miles RS, Amyes SGB. Laboratory control of antimicrobial therapy Chapter 8 medical microbiology. 14 ${ }^{\text {th }}$ edition. Edinburg Churchill Livingstone; 2007:151-177.

[15]. Clinical and Laboratory Standards Institute, Performance Standards for Antimicrobial Susceptibility Testing; $17^{\text {th }}$ informational supplement. M100-S17(2007), M2-A9, Vol 27 NO.1: P 23-138 (ISBN-I-56238-625-5), CLSI, 940 West Valey Road, Suite1400, Wayne, Pennsylvania 19087-1898 USA, 2007 